\title{
SENTIDO, MOBILIZAÇÃO E APRENDIZAGEM: AS RELAÇÕES DOS ALUNOS COM OS SABERES DAS LUTAS NAS AULAS DE EDUCAÇÃO FÍSICA
}

\author{
MEANING, MOBILIZATION AND LEARNING: STUDENT'S RELATIONS TO \\ MARTIAL ARTS KNOWLEDGE IN PHYSICAL EDUCATION CLASSES
}

\author{
SENTIDO, MOVILIZACION Y APRENDIZAJE: LAS RELACIONES DE LOS \\ ALUMNOS CON LOS SABERES DE LAS LUCHAS EN LAS CLASES DE \\ EDUCACIÓN FÍSICA
}

Marcos Roberto So*, Mauro Betti**

\begin{abstract}
Palavras chave Artes marciais. Conhecimento. Estudantes.

Resumo: Com base na teoria da relação com o saber, o objetivo desta investigação é compreender como os alunos se relacionam com os saberes das lutas nas aulas de Educação Física. Trata-se de um estudo de caso que se utilizou de entrevistas com alunos e docente, e observação de aulas. Os resultados apontam que relações identitárias e sociais condicionaram os sentidos iniciais e 0 interesse dos alunos pelas lutas, bem como as estratégias de ensino condicionaram a mobilização ou desmobilização para a aprendizagem. Conclui-se que 0 ensino de lutas na escola encontra-se permeado por tensões, sendo necessária a ressignificação dos preconceitos dos alunos, a (re)construção do conhecimento pedagógico deste conteúdo por parte do professor, e que a Educação Física como disciplina escolar deve inter-relacionar todas as figuras do aprender: saberobjeto, saber-domínio e saber-relacional.
\end{abstract}

Keywords:

Martial arts.

Knowledge.

Students.

Palabras clave: Artes marciales. Conocimiento. Estudiantes.

\begin{abstract}
Based on "relationship-to-knowledge theory", the purpose of this study is to understand how students relate to martial arts knowledge at Physical Education classes. It is a case study which used interviews with students and a teacher, and classroom observations. Results indicate that identity and socials relations conditioned students' initial impressions and interest towards martial arts, and teaching strategies conditioned mobilization or demobilization toward learning. Martial arts teaching in schools was found to be dominated by tensions. Student's preconceptions have to be re-framed; the teacher has to (re)construct pedagogical knowledge on that content; and Physical Education as a school subject should interrelate all the learning figures: object-knowledge, domainknowledge and relational-knowledge.
\end{abstract}

Resumen: Con base en la "teoría de la relación con el saber", el objetivo de esta investigación es entender cómo se relacionan los alumnos con los saberes de las luchas en las clases de Educación Física. Se trata de un estudio de caso que utilizó entrevistas con los alumnos y profesores, bien como observación de clases. Los resultados mostraron que relaciones identitarias y sociales condicionaron el sentido inicial y el interés de los alumnos por las luchas, así como las estrategias de enseñanza condicionaron la movilización o desmovilización para el aprendizaje. Se concluye que la enseñanza de luchas en la escuela se encuentra permeada por tensiones y que es necesario resignificar las preconcepciones de los alumnos, la (re)construcción del conocimiento pedagógico de este contenido por parte del profesor y que la Educación Física como disciplina escolar debe interrelacionar todas las figuras del aprender: saber-objeto, saber-dominio y saberrelacional.
*Instituto Federal de Educação, Ciência e Tecnologia do Sul de Minas. Pouso Alegre, MG, Brasil.

E-mail: marcosrobertoso@gmail.com

**Universidade Estadual Paulista (UNESP). Bauru, SP, Brasil.

E-mail: maurobettiunesp @ gmail.com

Recebido em: 01-02-2017 Aprovado em: 10-03-2018

DOI: http://dx.doi.org/10.22456/1982-8918.70995 (c) (1) (8) Licence 


\section{INTRODUÇÃO}

As lutas, uma das manifestações da cultura de movimento, têm se constituído como conteúdo próprio nas aulas de Educação Física (EF). Todavia, alguns fatores têm dificultado seu trato pedagógico nas escolas brasileiras. São eles: a) formação deficitária de professores, pois a pequena quantidade ou mesmo a ausência de conteúdos sobre lutas dificulta ao docente desenvolver o tema com segurança didático-pedagógica (NASCIMENTO; ALMEIDA, 2007; RUFINO; DARIDO, 2015); b) baixa produção acadêmico-científica que relaciona lutas e temas educacionais (CORREIA; FRANCHINI, 2010); c) a crença, por parte dos atores escolares, de uma suposta violência intrínseca das lutas (NASCIMENTO; ALMEIDA, 2007); d) dificuldades dos docentes em construir conhecimentos específicos e pedagógicos das lutas, de modo que predominam estratégias expositivas, exibição de vídeos, leituras de textos, e pouco tempo para a realização de movimentos corporais (SO; BETTI, 2012).

A maioria dessas assertivas foi construída a partir de perspectivas centradas nos docentes e suas intencionalidades pedagógicas, opiniões e representações sobre as lutas. É ainda incipiente a produção acadêmica que considera nesse contexto as relações que os alunos estabelecem com as lutas quando estas são propostas como conteúdos de ensino nas aulas de EF. Aliás, a perspectiva dos alunos sobre as aulas de EF (como eles as avaliam, como aprendem, como Ihes atribuem sentido) é, embora recente, abordagem relativamente volumosa na literatura especializada.

Betti e Ushinohama (2014) realizaram um levantamento dos estudos brasileiros sobre os temas (des)interesse, (des)motivação e (auto)exclusão nas aulas de Educação Física a partir das perspectivas dos alunos. Os resultados indicaram que a maior parte deles (cerca de 55\%) tinha caráter descritivo-quantitativo, nos quais estavam ausentes de quadros teóricos mais consistentes na geração dos dados e na sua interpretação. Apenas um dos estudos identificados valeu-se da teoria da relação com o saber de Charlot $(2000,2001)$. Nele, Schneider e Bueno (2005) evidenciaram a potencialidade da referida teoria para a compreensão das singularidades do que se ensina e do que se aprende nas aulas de Educação Física.

Considerar os saberes dos alunos e como constroem sentidos com o que a escola se propõe a ensinar (o "conteúdo") constitui "uma ruptura epistemológica fundamental", já que o ponto de partida não fica reduzido ao ensinar, pois abrange o aprender (CHARLOT, 2000). Assim, entendemos que as investigações pedagógicas não podem dissociar a aprendizagem do ensino, ou o professor do aluno, ou ainda tratar dos conteúdos em si mesmos, mas investir nas relações dessa tríade.

Assim, o objetivo desta investigação é compreender, com base na "teoria da relação com o saber" (CHARLOT, 2000, 2001), como os alunos se relacionam com os saberes das lutas nas aulas de EF. Com isso, espera-se elucidar algumas dificuldades nos processos de ensino e aprendizagem dessa manifestação da cultura de movimento.

O grande trunfo da teoria da relação com o saber é a compreensão de que somos, ao mesmo tempo, sujeitos sociais (em relação com a família, amigos, escola etc.) e singulares, 0 que é chamado por Charlot (2000), de "sociologia do sujeito".

Para Charlot (2000, p.51), "nascer significa estar submetido à obrigação de aprender" para pertencer a uma sociedade pré-estruturada. Por sua vez, aprender é um processo de 
apropriação autoproduzida "de uma humanidade que Ihe é 'exterior' [...] [que] exige a mediação do outro" (CHARLOT, 2000, p.54). No caso da escola, tal mediação está no "ensinar" dos docentes, uma ação externa (do outro) que precisa ir ao encontro de um movimento interior do aluno. A partir disso, Charlot sugere que a aprendizagem dependa de três elementos propulsores no sujeito: a mobilização, a atividade e o sentido.

A mobilização é reunir esforços para iniciar algo, é o "movimento interior do sujeito" (CHARLOT, 2001, p.26), e não exterior, gerado por algo ou alguém, como é o caso do conceito psicológico de motivação extrínseca. Logo, quem se mobiliza põe-se em movimento em uma atividade. Por sua vez, a atividade é compreendida como um conjunto de ações desencadeadas a partir de um móbil com objetivo de alcançar um fim, uma meta (CHARLOT, 2000). Entretanto, a mobilização pelas coisas do mundo é seletiva, já que o patrimônio humano é infinito e, consequentemente, seria impossível aprender tudo. Isto significa que o sujeito só se põe em movimento interior para as coisas que despertam interesse, de saberes que produzem sentidos.

Nesse pano de fundo, Charlot (2000) destaca a teoria da relação com o saber em três dimensões: epistêmica (a natureza do conhecimento), identitária (referente ao "eu") e social (referente a "nós").

$\mathrm{Na}$ dimensão epistêmica, como exemplifica Charlot (2001, p.22): "[...] não são os mesmos 'aprenderes' [...] que permitem ser um bom aluno e ser um líder em um bairro de subúrbio". Epistemicamente, o saber/aprender apresenta-se em três principais figuras (CHARLOT, 2000, 2001):

a) saber-objeto: representa um conteúdo linguisticamente enunciado. Por exemplo: expressões aritméticas, gramática, história do judô;

b) saber-domínio: consiste em dominar um objeto ou uma atividade. Por exemplo: aprender a nadar, aprender a fazer um rolamento do judô, a dar um golpe, amarrar uma faixa de judô;

c) saber-relacional: consiste no domínio de formas relacionais. Por exemplo: fazer amizades, cumprimentar um colega de treino nas aulas de judô.

Na dimensão identitária, a aprendizagem remete à singularidade do sujeito, quer dizer, o aluno não interioriza passivamente as coisas presentes no mundo, mas as que julga de maior valor e importância frente "às suas expectativas, às suas referências, à sua concepção de vida, às suas relações com os outros, à imagem que tem de si e à que quer dar de si aos outros" (CHARLOT, 2000, p.72).

Já a dimensão social considera que o sujeito vive em um mundo desigual, de diversas relações sociais, de diferentes culturas, e isso também induz a certos caminhos e relações com os saberes existentes no mundo. Portanto, a escola também pode ser considerada como um "lugar que induz relações com os saberes" (CHARLOT, 2001, p.18). Vale destacar que a relação social com o saber, para Charlot (2000), não é uma determinação, mas uma probabilidade de indução. Por exemplo, o fato de uma criança morar em uma comunidade conhecida por formar atletas de lutas não permite concluir que esta criança será também lutadora, mas possivelmente induzirá certas relações com os saberes das lutas.

Assim, a presente investigação buscou compreender como os alunos atribuem sentido e se mobilizam para aprendizagem das lutas nas aulas de EF, levando em conta as seguintes questões: a) Qual é/quais são, para os alunos, o(s) sentido(s) de aprender lutas nas aulas de 
EF?; e b) Qual/quais seria(m) a(s) fonte(s) de mobilização para se envolverem na aprendizagem das lutas nas aulas de EF?

Ademais, teve-se a expectativa de que os resultados possam indicar sugestões para favorecer a dinâmica de ensino e aprendizagem das lutas, contribuindo assim para sua efetiva incorporação nas aulas de EF.

\section{DECISÕES METODOLÓGICAS}

Esta investigação orientou-se pelo paradigma das pesquisas qualitativas em educação, e caracteriza-se como um "estudo de caso". Para Stenhouse (1998), a investigação educacional deve oferecer descrições aprofundadas e detalhadas para proporcionar um contexto comparativo frente a outros casos. $O$ estudo de caso é caracterizado por "investigação de uma unidade específica, situada em seu contexto, selecionada segundo critérios predeterminados e utilizando múltiplas fontes de dados, que se propõe a oferecer uma visão holística do fenômeno estudado" (ALVES-MAZZOTTI, 2006, p.650).

A presente investigação caracteriza-se pelos procedimentos e fundamentos do estudo de caso instrumental, delineado a partir de uma problemática objetiva e previamente definida. No caso instrumental decide-se primeiro "o que" pesquisar (problemática), e depois "onde", ou seja, a escolha do caso concreto (SANDÍN ESTEBAN, 2010).

Stake (2008) menciona que o interesse no caso instrumental se justifica por facilitar a compreensão de algo mais amplo, ao fornecer insights sobre um assunto, ou para contestar uma generalização amplamente aceita. Não se trata de apenas buscar compreender o caso em si, mas de esclarecer, contestar, criar ou refinar uma teoria ou hipótese.

Nesse sentido, o caso deve ser selecionado a fim de garantir maior relevância, isto é, a escola ou a turma não deve representar "apenas um local disponível para a coleta de dados" a ponto de ser facilmente substituída por outra (ALVES-MAZZOTTI, 2006, p.639). Ela deve ser realmente um "caso", com suas singularidades e complexidades que justifiquem sua relevância à compreensão.

A delimitação da nossa problemática de pesquisa exigiu selecionar uma turma de alunos que não havia aprendido o conteúdo "lutas" nas aulas de EF, o que nos permitiria analisar suas expectativas antes de se relacionarem com os saberes das lutas. A rede pública estadual de São Paulo da cidade de Bauru, localizada no centro-oeste do Estado, foi tomada inicialmente como locus para a seleção do caso, já que o conteúdo "lutas" está presente em cinco ocasiões ao longo do ensino fundamental II e médio no Currículo Oficial de Educação Física do Estado de São Paulo (CEF-SP) (SÃO PAULO, 2008).

Como no $7^{\circ}$ ano do ensino fundamental se dá o primeiro contato dos alunos com 0 conteúdo lutas (judô), este foi o ano escolar eleito. Outro critério considerou a história de vida do(a) professor(a), e levaria à eleição de docentes que não foram ou são praticantes/atletas de qualquer modalidade de luta, pois um atual ou ex-praticante de lutas possuiria conhecimentos específicos e diferenciados sobre o conteúdo, situação incomum à maioria dos professores de EF.

A escola selecionada localiza-se na periferia da cidade e contava com três professoras de EF; no entanto, apenas uma ministrava aulas nas turmas de $7^{\circ}$ ano. A turma investigada tinha 31 alunos, composta por 16 meninas e 15 meninos. 
A escola contava com um espaço físico privilegiado: salas de aula, vídeo, ambiente, artes e leitura, duas quadras poliesportivas (coberta e descoberta), pátios e laboratórios de informática e ciências. Apesar da diversidade de espaços, as aulas de lutas aconteceram na sala de vídeo e na sala ambiente (sala multidisciplinar com amplo espaço físico).

As aulas de EF ocorriam duas vezes na semana, com duração de 50 minutos por aula. 0 trabalho de campo teve a duração de três meses, totalizando 21 visitas à escola1.

\subsection{Procedimentos}

Após contato inicial e familiarização ao ambiente da escola, o trabalho de campo contemplou três etapas:

a) Entrevista inicial semiestruturada, registrada em gravador de voz:

- com a professora do $7^{\circ}$ ano do ensino fundamental, sobre os temas: formação acadêmica, opinião sobre o conteúdo lutas no CEF-SP;

- com 12 alunos da turma do $7^{\circ}$ ano, selecionados de maneira aleatória, por sorteio. As perguntas trataram dos seguintes aspectos: histórico de práticas de lutas; expectativas e opinião em relação ao conteúdo lutas;

b) Observação das aulas que contemplaram o conteúdo judô, com registro em diário de campo;

c) Entrevista final semiestruturada, registrada em gravador voz:

- com os 12 alunos selecionados inicialmente, mais cinco escolhidos intencionalmente pelo pesquisador, a partir de indícios provenientes das observações de campo, que os qualificaram como possíveis bons informantes - dois alunos de intensa mobilização nas aulas, e três que participaram pouco das aulas. As perguntas trataram dos seguintes aspectos: opinião em relação às aulas do conteúdo lutas; o que aprenderam nas aulas; interesse em relação às lutas;

- com a professora, sobre o detalhamento de situações ocorridas em aula.

Os alunos estão identificados por pseudônimos escolhidos pelo pesquisador. Aqueles que declararam ter vivenciado lutas fora da escola receberam pseudônimos de personagens do universo das lutas, tais como super-heróis, artistas marciais e deuses da mitologia grecoromana. Já os alunos sem vivência prévia em lutas foram identificados com nomes habituais.

\section{RESULTADOS, ANÁLISE E DISCUSSÃO}

A partir das transcrições das falas na entrevista inicial pudemos acessar as expectativas dos discentes antes das aulas de lutas. Assim, dos depoimentos de 12 alunos entrevistados, inicialmente emergiram dois perfis: a) os que já praticaram lutas em ambiente extraescolar (sete de 12 entrevistados); b) e os que não tinham vivência corporal em lutas (cinco de 12 entrevistados).

Para os alunos que já tinham vivência prévia em lutas, o conteúdo representava uma prática corporal esportiva ou de defesa pessoal contra adversidades da vida e, portanto, esperavam a aprendizagem de elementos técnico-táticos (golpes e estratégias): "Luta para mim é defesa, ensina você além de se defender [...] quando precisar, você sai batendo na pessoa" (Elektra). Ou para Atena: "Luta é tipo de um jogo [...] que a gente mais aprende para poder jogar nos campeonatos".

1 Esta investigação foi aprovada no Comitê de Ética em Pesquisa da Universidade Estadual Paulista (UNESP). 
Já aqueles sem vivência em lutas caracterizaram-nas como prática violenta que poderia causar danos físicos a si próprios e aos outros; por isso, suas expectativas pautavam-se por sentimentos relacionados ao medo de sofrer violência e ao receio de machucar-se:

O futebol a gente tá brincando, jogando. Na luta não, a gente tá batendo (Paulo).

Luta é chata, só vê a pessoa apanhando e aí sai sangue (Ana).

É uma briga [...] machuca, vai ficar roxo, a perna, o braço [...] [Espero] algum choro [...] o aluno não vai gostar ao levar um golpe (Anderson).

É uma coisa agressiva, um método que machuca (Talita).

Golpe pode machucar [...] quebrar um braço, alguma coisa quebra [...] quero que ela (professora) passe tipo regras, e também luta [...] de não machucar (Morfeu).

Tal percepção negativa das lutas compactua com Nascimento e Almeida (2007), para quem os professores e gestores justificam a exclusão das lutas nas aulas de EF pela sua suposta violência intrínseca.

Identificamos inicialmente a polarização dos alunos entre interessados e desinteressados pela aprendizagem das lutas, o que pode ser justificado por suas relações prévias com tal manifestação, quer dizer, suas características identitárias e sociais. Os que já tinham vivenciado lutas anteriormente manifestaram interesse, e o contrário ocorreu com aqueles que não as vivenciaram; ou seja, nesse momento, as relações de sentido para com as lutas decorriam das diferentes histórias de vida.

$\mathrm{Na}$ fase seguinte foram observadas as quatro aulas que contemplaram o judô. Embora - CEF-SP proponha que o judô seja abordado entre seis e oito aulas (SÃO PAULO, 2009), a redução da quantidade de aulas representou uma adequação da professora em relação ao currículo oficial.

Na primeira aula, a docente optou por uma aula expositiva que abordou diversos temas do judô, com uso de slides e vídeos. Na segunda aula, a professora propôs dois jogos de lutas: um "cabo de guerra" sem corda e a "briga de galo". Na terceira aula, a professora apresentou 0 golpe o-soto-gari do judô, seguido da prática do golpe pelos alunos, em duplas. Na quarta aula, a professora propôs uma avaliação escrita.

A triangulação dos dados empíricos gerados nas entrevistas iniciais, na observação das aulas de judô e nas entrevistas finais revelaram condições, situações e condutas (docentes e discentes) tanto favoráveis como desfavoráveis à mobilização dos alunos em relação às lutas, além de um elemento ambíguo, conforme Quadro 1.

Quadro 1 - Elementos que favoreceram e dificultaram a mobilização dos alunos

\begin{tabular}{|c|c|}
\hline Elementos que favoreceram a mobilização & Elementos que dificultaram a mobilização \\
\hline Jogos de lutas & Medo de machucar-se \\
\hline Aprendizagem de um golpe de judô & $\begin{array}{c}\text { Vergonha de expor habilidades das lutas para os } \\
\text { colegas }\end{array}$ \\
\hline Mediação da professora & Quantidade insuficiente de aulas \\
\hline $\begin{array}{c}\text { Mediação dos alunos que tinham vivência prévia em } \\
\text { lutas }\end{array}$ & Aula em formato de saber-objeto \\
\hline Aulas em formato de saber-domínio & Longo tempo de espera entre as atividades \\
\hline Elemento ambíguo: a periferia do dojo & \\
\hline
\end{tabular}




\subsection{Elementos favoráveis à mobilização}

Com relação aos elementos favoráveis à mobilização, os jogos de lutas realizados na segunda aula minimizaram o sentimento associado ao medo de machucar-se, o qual constatamos nos depoimentos iniciais dos alunos. 0 caráter lúdico dessas atividades foi elemento central para dissociar a luta de danos físicos, conforme alguns depoimentos:

Eu esperava que fosse só brigar, bater, mas não é. A professora colocou brincadeira, a gente se divertiu muito (Talita).

Eu queria fugir da sala por causa que eu não queria fazer, mas depois comecei a gostar. No primeiro exercício que ela passou, que era de cabo de guerra. Foi diferente, foi brincando (Ana).

Porque eu achava que era briga, essas coisas, sabe? Algo muito violento, mas não, não é (Lucas).

Nesse sentido, é importante ressaltar que os jogos de luta podem ser utilizados como um período de adaptação e familiarização ao judô, do mesmo modo que, analogicamente, não é adequado propor um nado técnico e específico para um iniciante na natação; pelo contrário, preconiza-se nas primeiras aulas uma "adaptação ao meio líquido".

Outro elemento favorável à mobilização, conforme a fala dos alunos, foi a inclusão da aprendizagem do golpe o-soto-gari na terceira aula. O referido golpe foi o conteúdo mais citado quando questionado aos discentes sobre o que aprenderam nas aulas. Tal aprendizagem também concedeu o status de "saber lutar" e "saber derrubar alguém", já que muitos alunos não referenciavam o golpe pelo seu nome ou pela sua execução, mas pela sua utilidade:

Eu aprendi a me defender, aprendi coisas que eu não sabia que podia usar, ou que eu podia fazer [...]. Tipo derrubar uma pessoa eu não sabia (Talita).

Eu aprendi a lutar (Morfeu).

Que eu aprendi a me defender (Ana).

Tais relatos remetem a Charlot (2000), para quem aprender é apropriar-se do mundo para construir-se como sujeito humano, de maneira que essa apropriação favorece 0 adentramento à uma comunidade de pessoas que compartilham do mesmo saber.

Dessa forma, "saber lutar" e "saber derrubar alguém" representam o ingresso à uma comunidade exclusiva de pessoas que partilham dos saberes das lutas. Nesse sentido, tal aprendizagem poderá fazer sentido em algum momento de suas vidas, como evidenciou Bruce Lee: "[...] quando a professora começou a fazer as aulas, eu falei: - Mãe, eu gostei da aula de judô, me põe no judô?".

No entanto, 0 ato de "saber derrubar alguém" também pode ser interpretado como uma ação relacionada à eventual necessidade de defesa pessoal, como constatado na entrevista inicial. Tal representação por parte dos alunos reforça a sugestão apresentada por Olivier (2000), bem como do próprio CEF-SP, de problematizar a associação das lutas com violência, brigas de rua etc.

O golpe o-soto-gari não estava incluso nas orientações do CEF-SP. Questionada sobre isso, a professora mencionou que consultou colegas de trabalho praticantes de lutas, os quais sugeriram o ensino do referido golpe por ser de fácil execução. Portanto, ao invés de "aplicar" ou ignorar as sugestões curriculares, a professora optou por modificá-las, o que só foi possível sob a mediação dos saberes docentes, seus e de outros colegas. 
A mediação da professora foi apontada pelos alunos como um elemento favorável à mobilização:

\author{
O jeito que ela ensina é diferente (Ana). \\ A professora explicou mais, dai eu quis lutar pra ver como é. Pra ver se é violento \\ ou não, aí eu achei que não era violento, não (Paulo). \\ Ela explicou certinho como que era a luta e eu não sabia antes. Aí eu vi que era \\ legal e deu interesse (Liliana).
}

Nesse sentido, como bem aprofundou a aluna Elektra, a conduta da professora foi diferenciada em relação ao ensino de outros conteúdos: "No vôlei, ela falava uma regra básica e a gente ia treinar, falava outra e a gente ia. Aqui não, ela explicou, mostrou, mostrou de novo e depois a gente foi. E na hora que tava aplicando o golpe, se errava, ela explicava de novo".

Além da mediação dos saberes docentes, outro elemento essencial para a mobilização de alguns alunos mais inseguros com a prática de lutas foi a persuasão dos colegas de sala que tinham mais familiaridade com o conteúdo, conforme os depoimentos a seguir:

No princípio, minha amiga [Atena] falou: - Vamos, Elektra, porque eu quero te derrubar (Elektra).

Os moleques que me chamaram para ir e eu fui (Morfeu).

Os outros tavam tudo falando que iam praticar, daí eu não queria ficar sozinho (Anderson).

Em ambos os casos de mediação (professora e colegas de turma), pode-se remeter a Charlot (2000), para quem o homem, na busca constante de construção de si mesmo, necessita de mediadores (livros, pessoas, amigos, professores) responsáveis por aproximar mundo e sujeito.

Portanto, podemos inferir que para a mobilização dos alunos que resistiram inicialmente a participar das aulas foi também importante a relação com o "outro" detentor de saberes das lutas, seja um colega ou o próprio professor.

De modo geral, as aulas que abrangiam o "saber-domínio", ou seja, o movimento como elemento central da aprendizagem, ocasionaram maior mobilização entre os alunos do que as aulas expositivas, o que é evidenciado pelo fato de que o o-soto-gari e os jogos de lutas foram os conteúdos mais citados:

Para falar verdade, não gostei muito, não [aula expositiva]. Seria melhor ela tá explicando com as palavras dela (Stallone).

Eu acho que a professora podia ir mais na prática porque antes [primeira aula] a gente tava sempre na sala (Elektra).

Não prestei muito atenção [...] porque eu não gosto de aula teórica (Atena).

\title{
3.2 Elementos que dificultaram a mobilização
}

Alguns elementos dificultaram a mobilização dos alunos. Sobretudo entre as meninas, o medo de machucar-se e a vergonha de expor as habilidades frente aos meninos foram os argumentos mais citados nas entrevistas. Vale ressaltar que o medo de se machucar esteve relacionado às atividades que envolviam quedas no solo: 
Não é nem problema de força de vontade, é mais por medo mesmo. De ir e acontecer alguma coisa [...] de machucar (Julia).

Eu fiquei meio indecisa e fiquei perto da professora, daí eu falei: - Ah, eu vou! Aí depois, eu olhei a pessoa que eu ia, e falei: - Ah, não vou mais (Elisabete).

Uchoga e Altmann (2016) mencionam que as tentativas de se arriscar em novos movimentos corporais nas aulas de EF são distintas entre meninas e meninos. Dentre os principais motivos estão o desconforto com movimentos considerados difíceis e sua frequente associação com o medo de machucar-se. De fato, no atual estudo, os meninos ousaram mais do que as meninas, não pela ausência de "medo de machucar-se", mas por dois motivos relatados por alguns alunos: a) não integrar-se ao ambiente feminino: "Quase todos moleques fez e eu não ia ficar com as meninas" (Anderson); b) o exercício da virilidade: "Ó, eu aprendi também que [judô] não é difícil, é muito fácil. Mas tem que ser preparado pra dor, como doeu quando o Chuck Norris me derrubou" (Hulk).

Nesse sentido, a professora tentou minimizar o receio de machucar-se na terceira aula, ao adaptar um tatame com colchonetes e placas de EVA. Todavia, a quantidade de material foi insuficiente para gerar a sensação de segurança, de que as quedas não provocariam dor e machucados.

A vergonha de algumas meninas em expor suas habilidades, supostamente inferiores às dos meninos, também levou a um menor nível de mobilização: "fazer alguma coisa errada e os moleques começarem a zoar [...] na luta você já tá num espaço pequeno [...] todo mundo olhando, dá mais vergonha ainda [...]" (Elektra).

Essa inquietação corrobora o apontamento de Altmann (1998), ao admitir que a inibição, a timidez e a vergonha são mais intensas quando há vigilância exercida por gêneros diferentes. Nesse caso específico, esses sentimentos foram potencializados pela suposta posição de "superioridade" dos meninos perante as meninas nas lutas, justificada por elas com argumentos sexistas:

Ah, pelos fatos deles terem essas brincadeirinhas, vou dizer estúpidas, um com outro assim, eles já levaram mais na brincadeira, começam dá soco assim (Elisabete).

Porque acho que a luta é mais masculina assim [...] o masculino já nasce assim com negócio de lutar, de briga, essas coisas. Então, é o sexo mais forte [...]. Então acho que eles se interessaram mais (Liliana).

Os meninos não vão ter o que fazer, vão ficar olhando as meninas derrubar uma com a outra (Elektra).

A vergonha de algumas meninas em se expor à vigilância dos colegas foi potencializada pela estratégia adotada no processo de ensino do golpe o-soto-gari, qual seja, a prática do golpe entre dois alunos, na qual uma dupla a cada vez se dirigia ao centro da sala para executar o o-soto-gari sob orientações da professora, e os demais ficavam observando. Embora tenha facilitado o trabalho docente quanto ao controle da situação e auxílio individual aos alunos, 0 longo tempo de espera gerou insatisfação nos alunos:

A professora pegou uma dupla [...] mas as pessoas que queriam ir de novo ficaram querendo ir. Não deu pra ir mais vezes (Elektra).

Muitas pessoas ficaram sentadas [...] enquanto o outro lutava, e não prestou muita atenção por não tá praticando (Elisabete). 
Charlot (2009, p. 151) identifica uma "desigualdade social perante a escola", já que se trata de uma instituição que impregna valores ocultos e implícitos predominantemente masculinos. No caso dos saberes das lutas, há também uma desigualdade social diante do saber. Isto é, as relações sociais de meninas e meninos também condicionam o interesse e a mobilização; contudo, não podem determiná-los. É nesse sentido que a escola e a EF podem ofertar situações de aprendizagem que subvertam tais desigualdades sociais, construindo novas possibilidades de relações de sentido.

Outro fator que dificultou a mobilização dos alunos foi a quantidade insuficiente de aulas, na opinião de nove dos 17 entrevistados:

A professora poderia ter ensinado mais de golpe pra gente, também (Paulo).

Acho que ela devia ter ensinado mais golpes. Foi pouco (Hulk).

Eu acho que poderia a gente ter aprendido um pouco mais e ter tido mais tempo. [...] Um pouco mais sobre os golpes, não sobre os golpes em si, mas praticar os golpes (Elektra).

O fato de que apenas duas das quatro aulas foram dedicadas à prática de movimentos de judô acarretou dificuldades de adaptação e familiarização ao conteúdo para aqueles alunos que tinham medo de machucar-se. É o caso de Elisabete, que não participou corporalmente das aulas, embora estivesse disposta a tal, mas sua disposição foi concretizada em outra situação:

Eu mostrei o que aprendi [para meu pai] [referência ao o-soto-gar] [...] mesmo sem ter participado da aula de Educação Física. [...] Foi um pouco difícil de derrubá-lo, mas consegui [...]. [Se houvesse próxima aula] poderia brincar com mais coragem [...] Tentei e conseguil Aí perdi o medo.

Entendemos que o gerenciamento na distribuição das aulas refletiu a limitação do conhecimento específico do conteúdo lutas por parte da professora, já que, conforme evidenciaram as entrevistas, ela guiou-se predominantemente pelo estudo de enunciados linguísticos (saber-objeto), como é o caso das orientações do CEF-SP e do material proveniente das mídias (internet, televisão).

Tal resultado compactua com a investigação de So e Betti (2012), que analisaram como uma professora sem vivência em lutas constrói conhecimentos específicos e pedagógicos sobre o conteúdo. Os resultados apontaram que predominaram estratégias de ensino que utilizavam a exposição verbal, por parte do professor, de aspectos conceituais e, em contrapartida, poucas estratégias envolveram a execução de movimentos.

Além disso, quando questionamos os alunos sobre o que aprenderam nas aulas de lutas, houve poucas respostas referidas aos conteúdos da aula expositiva (primeira aula). Por outro lado, predominaram largamente as referências aos conteúdos presentes nas duas aulas dedicadas à prática de movimentos.

Sendo assim, o grande desafio da EF é mediar e relacionar o saber-objeto (discurso) com o saber-domínio (saber-fazer). Dessa forma, sugerimos que as aulas expositivas sejam articuladas às situações de vivência corporal, como sugerido pelos alunos: "A parte teórica [referência à aula expositiva] que eu me lembre, acho que eu não tive [na academia de caratê]. Eu fui direto na prática, tanto que eu aprendi o esquema de faixas na prática" (Chuck Norris).

No entanto, é preciso enfatizar que não entendemos a EF como disciplina que lida exclusivamente com o saber-domínio, secundarizando o saber-objeto e o saber-relacional. 
Pelo contrário, não é o conteúdo da disciplina em si, seja ela EF ou outra, que é um saberobjeto, um saber-domínio ou um saber relacional, mas é o modo de ensinar escolhido pelo professor que pode privilegiar uma das figuras do aprender. Logo, ao invés de vincular a EF a somente uma figura do aprender, é preciso reconhecer que é uma disciplina que inter-relaciona todas as figuras: saber-objeto, saber-domínio e saber-relacional.

\title{
3.3 Um elemento ambíguo: a periferia do dojo
}

"Ambíguo", conforme Houaiss (2009), é algo "que tem (ou pode ter) diferentes sentidos" ou "que admite interpretações diversas". Nesse sentido, identificamos um elemento de ambiguidade nas aulas: a periferia do dojo².

A estratégia utilizada pela professora no ensino do golpe o-soto-gari, como já mencionado, gerou um longo tempo de espera para os alunos. Nessa situação, os alunos muitas vezes abandonaram a atividade principal (execução do golpe no centro da sala) e reuniramse em um espaço no fundo da sala para a prática de movimentos de lutas - espaço e tempo este que denominamos "periferia do dojo". Essa expressão inspirou-se em Oliveira (2010), que em pesquisa de campo constatou que vários alunos, motivados por conflitos de gênero, fuga da rígida rotina da escola ou para se dedicarem a alguma prática corporal, afastavam-se da atividade principal das aulas de EF em direção a um espaço que denominou "periferia da quadra". Em tal espaço, sem a supervisão do professor, os alunos criaram uma intensa rede de sociabilidade e aprendizagem, o que também foi observado neste estudo.

A maioria dos alunos participou em algum momento da periferia do dojo. Mas apenas cinco deles (Bruce Lee, Ranger Verde, Chuck Norris, Carl Johnson e Atena) participaram de maneira mais intensa, ou seja, exercendo papéis ativos na realização e compartilhamento de golpes do judô, todos eles com vivência anterior em lutas. Conforme declarou Ranger Verde: "Eu queria aprender mais golpes, como se defender, queria ter mais técnica". Já os demais alunos participaram como coadjuvantes (torcida, arbitragem, gravação de vídeos etc.). A periferia do dojo representou tempo-espaço de intensificação de relações interpessoais, de circulação de saberes e de aprendizagem sobre conteúdos da EF.

No caso desta investigação, o que apareceu na periferia do dojo, em termos de condutas e discursos, foram temas relacionadas à mídia, gênero, violência e esporte. No entanto, tais temas tenderam a reforçar os estereótipos e representações sociais mais comuns no que diz respeito às lutas: violência, machismo, espetacularização, exclusão.

Um exemplo disso é o episódio de violência física perpetrado por Carl Johnson em Bruce Lee na periferia do dojo:

\begin{abstract}
Quando eu tava jogando com outra pessoa [...] eu tava de joelhos. O Stallone tava me ensinando a lutar jiu-jítsu de joelhos. Daí [...] ele [Carl Johnson] me deu um mata leão [por trás] [...] bati três vezes, mas ele não largava daí meus amigos soltou [...]. Daí eu falei assim: - Para, para, para, com a voz fina, daí ele me largou.
\end{abstract}

Conforme Olivier (2000), a violência toma parte nas relações sociais, pois seria um modo de expressão e comunicação em reação a interações sociais que geram estresse e frustração. Desse modo, para o referido autor, não cabe pretender eliminar toda expressão 
de violência, mas oportunizar situações de sentido para reflexão, como: que violências sofro? Qual violência suporto? Que violência é socialmente permitida?

Sob esse pano de fundo, Olivier (2000) sugere que a EF e a escola proponham a transferência das brigas para jogos de lutas com regras, o que definitivamente não foi o que ocorreu na periferia do dojo, pois dois elementos desse tempo-espaço impediram tal dinâmica: a não diretividade da atividade e a ausência de regras que inibissem a violência.

No âmbito escolar, a frequente associação das lutas com a violência pode ser uma oportunidade para estabelecer relações de sentido e mobilização de modo a ressignificar discursos para os quais "luta é violenta"; "luta é coisa de marginal"; "luta machuca".

Daí a importância da mediação e intervenção do professor para provocar a problematização e reflexão sobre esses temas e suas manifestações sociais. Então, apesar da periferia do dojo ter representado um tempo e espaço de intensa rede de sociabilidade (principalmente para os mais habilidosos), decorreu sob a reprodução de estereótipos ligados às lutas, o que dificultou a participação efetiva e protagonista dos demais discentes.

\section{CONCLUSÕES}

Apesar da inclusão formal das lutas nos currículos oficiais de diversos estados e munícipios, o ensino de lutas na escola ainda se encontra em um campo de tensões que mais favorece sua exclusão que inclusão na EF Escolar. 0 entendimento, por parte dos alunos, de que as lutas são violentas, relacionadas ao gênero masculino e causadoras de danos físicos compromete a participação discente. Antes do início das aulas, foi perceptível um imaginário negativo dos alunos sem vivência em lutas: luta é algo violento, que causa traumas. A recusa inicial do conteúdo por grande parte dos alunos foi substituída pelo um ingresso a uma comunidade de pessoas que partilham do mesmo saber, neste caso, das lutas. 0 trato das lutas no contexto educacional reforça o fato de que a escola não pode ser "um lugar que recebe alunos dotados destas ou daquelas relações com os saberes, mas é, também um lugar que induz relações com os saberes" (CHARLOT, 2001, p.18).

Diante disso, afirmamos que a função da EF é tematizar os elementos da cultura de movimento à luz de critérios didático-pedagógicos. No caso das lutas, tal tematização demanda inicialmente superar tais preconceitos e ressignificá-los; depois, demanda a (re)construção do conhecimento pedagógico do conteúdo por parte do professor. Para tal, como demonstrou esta investigação, é imprescindível compreender o processo de ensino e aprendizagem sob o ponto de vista dos alunos, analisando-os como sujeitos sociais e singulares.

Se a mobilização pelos implementos do mundo é seletiva e somente decorre a partir de coisas que despertam interesse e de saberes que produzem sentido, seria necessário compreender melhor essas relações para tornar as aulas mais interessantes, provocadoras e sensíveis, de modo que consigam estabelecer uma relação de mobilização, sentido e desejo com o mundo, consigo mesmo e com outros (CHARLOT, 2000, 2001).

Nesse sentido, esta investigação forneceu algumas pistas para melhorar a construção de conhecimento pedagógico e assim favorecer a intervenção do professor:

- Os jogos de lutas podem minimizar o medo de machucar-se.

- A organização da prática em diversas duplas simultâneas evita a sensação de vergonha entre os alunos. 
- Maior quantidade de aulas pode facilitar o processo de familiarização com o conteúdo.

- Os alunos que possuem vivência em lutas podem ser "mediadores" na relação com os demais colegas.

- Privilegiar situações de aprendizagem que envolvam movimento corporal.

- Dar maior atenção para a participação das meninas.

- Contextualizar e tematizar questões de gênero; por exemplo: homens e mulheres podem praticar lutas? Por que poucas mulheres praticam lutas? A prática de lutas pode definir sexualidade?

- Incluir elementos problematizadores acerca dos temas "violência", "briga" e "luta" para que um movimento ou golpe não seja limitado à interpretação de "saber derrubar alguém".

Por fim, é preciso enfatizar que pesquisas "sobre" os alunos não se limitam à descrição de gostos e opiniões discentes. Pelo contrário, quando analisamos a relação dos alunos com o saber, identificando suas relações de sentido, mobilização e atividade no contexto educacional, as conclusões retornam aos professores, constatando e sugerindo dinâmicas e diretrizes para a construção de seus conhecimentos específicos, pedagógicos e curriculares do/sobre 0 conteúdo.

\section{REFERÊNCIAS}

ALTMANN, Helena. Rompendo fronteiras de gênero: Marias (e) homens na educação física. 1998. 111f. Dissertação (Mestrado em Educação) - UFMG, Belo Horizonte, 1998.

ALVES-MAZZOTTI, Alda Judith. Usos e abusos do estudo de caso. Cadernos de Pesquisa, v. 129, p.637-651, 2006. Disponível em: <http://www.scielo.br/pdf/cp/v36n129/a0736129.pdf>. Acesso em: 24 abr. 2016.

BETTI, Mauro; USHINOHAMA, Tatiana Zuardi. Os saberes da Educação Física nas perspectivas dos alunos: panorama da literatura e uma proposta de investigação a partir da 'teoria da relação com o saber'. Revista Pulsar, v.6, n.4, p.1-18, 2014.

CHARLOT, Bernard. Da relação com o saber: elementos para uma teoria. Porto Alegre: Artmed, 2000.

CHARLOT, Bernard. Os jovens e o saber: perspectivas mundiais. Porto Alegre: Artmed, 2001.

CHARLOT, Bernard. A escola e o trabalho dos alunos. Sísifo/Revista de Ciências de Educação, n.10, p.89-96, 2009.

CORREIA, Walter Roberto; FRANCHINI, Emerson. Produção acadêmica em lutas, artes marciais e esportes de combate. Motriz, v.16, p.1-9, 2010. Disponível em:<http://www.periodicos. rc.biblioteca.unesp.br/index.php/motriz/article/view/2800/2707>. Acesso em: 20 abr. 2016.

HOUAISS, A. Dicionário eletrônico Houaiss da língua portuguesa. Rio de Janeiro: Objetiva, 2009.

NASCIMENTO, Paulo Rogério Barbosa do; ALMEIDA, Luciano. A tematização das lutas na Educação Física Escolar: restrições e possibilidades. Movimento, v.13, n.3, p.91-110, set/dez 
2007. Disponível em: <http://seer.ufrgs.br/index.php/Movimento/article/view/3567/1968>. Acesso em: 10 abr. 2016.

OLIVEIRA, Rogério Cruz de. Na "periferia" da quadra: Educação Física, cultura e sociabilidade na escola. 2010. 201f. Tese (Doutorado em Educação Física) - Faculdade de Educação Física da UNICAMP, Campinas, 2010.

OLIVIER, Jean-Claude. Das brigas aos jogos com regras: enfrentando a indisciplina na escola. Porto Alegre: Artmed, 2000.

RUFINO, Luiz Gustavo Bonatto; DARIDO, Suraya Cristina. O ensino das lutas nas aulas de Educação Física: análise da prática pedagógica à luz de especialistas. Revista de Educação Física/UEM, v.26, n.4, p.505-518, 4 trim. 2015. Disponível em: <http://periodicos.uem.br/ojs/index. php/RevEducFis/article/view/26441/15525>. Acesso em: 29 set. 2016.

SANDÍN ESTEBAN, Maria Paz. Pesquisa qualitativa em educação: fundamentos e tradições. Porto Alegre: Artmed, 2010.

SÃO PAULO (Estado). Proposta curricular do Estado de São Paulo: educação física - ensino fundamental ciclo Il e ensino médio. São Paulo: SEE, 2008.

SÃO PAULO (Estado). Caderno do professor: educação física, ensino fundamental - $7^{\circ}$ ano $/ 4^{\circ}$ bimestre. São Paulo: SEE, 2009.

SCHNEIDER, Omar; BUENO, José Geraldo Silveira. A relação dos alunos com os saberes compartilhados nas aulas de educação física. Movimento, v. 11, n. 11, p. 23-46, jan./abr., 2005. Disponível em: <http://www.seer.ufrgs.br/index.php/Movimento/article/view/2860/1474> >. Acesso em: 18 jan. 2018.

SO, Marcos Roberto; BETTI, Mauro. Saberes docentes: o tema lutas no Currículo de Educação Física do Estado de São Paulo. In: TOMMASIELLO, Maria Guiomar Carneiro et al. (Org.).

Didática e práticas de ensino na realidade escolar contemporânea: constatações, análises e proposições. Araraquara-SP: Junqueira\&Marin, 2012. v.1, p.1-12.

STAKE, Robert E. Case Studies. In: DENZIN, Norman; LINCOLN, Yvonna. Strategies of Qualitative Inquiry. 3.ed. Thousand Oaks: Sage, 2008. p. 119-150.

STENHOUSE, Lawrence. Investigación y desarollo del curriculum. 4.ed. Madrid: Morata, 1998.

UCHOGA, Liane Aparecida Roveran; ALTMANN, Helena. A educação física escolar e relações de gênero: diferentes modos de participar e arriscar-se nos conteúdos de aula.

Revista Brasileira de Ciências do Esporte. 2016. Disponível em: <http://cev.org.br/arquivo/ biblioteca/4032345.pdf>. Acesso em: 18 jan. 2018.

\section{Apoio financeiro:}

Este artigo é oriundo de dissertação de mestrado do primeiro autor, e financiado pela Fundação de Amparo à Pesquisa do Estado de São Paulo (FAPESP). 